\title{
Empirical Analysis of the Relationship between HR Professionals' Competency and Enterprise Performance
}

\author{
Hui LIU ${ }^{1, a,{ }^{*} \text {, Yong FU }}{ }^{2, b}$, Xing WANG ${ }^{3, c}$, Yin FANG ${ }^{4, d}$ \\ 1,2,3,4 Faculty of Management, Southwest University for Nationalities, Chengdu, China

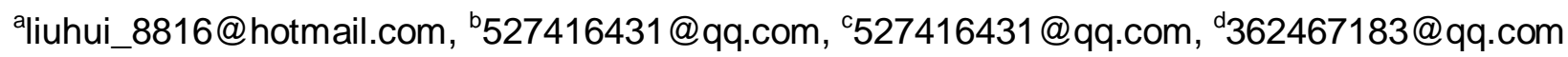 \\ ${ }^{*}$ Corresponding author
}

Keywords: HR professionals' competency, Enterprise performance, HRBP.

\begin{abstract}
The research of competency is one of the hot issues in the area of HRM at present. On the basis of existing research, this study adopts the measuring scale of HR professionals' competency in enterprises of China which was developed by Chen Wansi, Ren Wei and Yao Shengjuan to make a survey on HR professionals' competency of the enterprises in Guangzhou and Foshan region. In this study, we found that the competency of winning support, effective allocation, inspiration, HRM knowledge, HRMIS(human resource management information system) application and business knowledge are significantly related to the enterprise performance. In allusion to this situation, we give same corresponding suggestions to improve the competency, and then promote the enterprise performance continuously.

Human resource is one of the core resources which obtain the competitive advantages for enterprise. HR professionals play an important role in the enterprise competition, and they can increase the value of enterprise by their competency promotion. Both in academia and enterprise management practice, improving employees' competency has become a consensus. But it requires different competency in different industry, enterprise and position, so it's necessary to make an in-depth study of competency for specific industries and positions. In order to analysis the relationship between HR professionals' competency and enterprise performance, this study selected the HR professionals from petrochemical trade enterprises in Guangzhou and Foshan region as the sample. And we found the competency factors which have great influence on enterprise performance in this industry through questionnaire survey and empirical analysis. We hope the analysis result can help enterprises improve their HR professionals' competency and then promote their performance continuously.
\end{abstract}

\section{Review of the literature}

\section{Competency}

The concept of competency was first put forward by McClelland (1973) in his article "Testing for competency Rather Than Intelligence". He considered that the competency was the knowledge, skill, ability, qualities and motivation which was relevant to work, performance or any other important achievements in life directly. [1] He suggested that the traditional ability tests like intelligence test should be replaced by competency test. Spencer (1993) considered that competency was the basic potential characteristics which referred to the standard performance. It was the basic potential characteristics which was underlying and stable. And it was related to the position and could help to understand its anticipative or actual reflection and forecast the performance. [2] Later, some scholars started to research the relationship between the competency and enterprise performance. Ulrich, Brockbank and Yeung(1995) considered that competency could add value to enterprises, but it must focus on the changing environment so as to support the enterprises to achieve competitive advantages.[3] Wang Chongming (2000), a professor of Zhejiang University (2000), published a paper in the journal management psychology. He considered that competency was knowledge, skills, abilities and values, personality, motivation and other characteristics (KSAOs) which lead to a high performance.[4]Professor Peng Jianfeng (2003) of Renmin University of China argued that competency is an aggregate of ability, and qualifications, and an aggregate of personal traits which 
encouraged the staff to produce good performance. It reflected that the staff could exert their skills, knowledge, personality characteristics and driving force in different ways. [5]

Comprehensively, competency has three key characteristics as follows: (1) Correlate to work. The competency is the individual characteristics associated with the job; (2) distinguish the performance. The competency can make a performance distinction between outstanding staff and average ones; (3) correlate to performance. Competency is related to the work performance on a causal relationship and can forecast employees' performance in the future.

\section{Competency of HR professionals}

According to the "Enterprise Human Resources Management Professional Standards of the State" (professional code: 2-02-34-07) which was promulgated by the ministry of labor and social security of China in 2001, the HR professional was defined as professional managers who engaged in human resource planning, recruitment, performance management, compensation management, motivation, training and development, labor relations coordination. [6] Obviously, HR professionals in this country is mainly refers to the person who works in enterprise. The study of the HR professionals' competency is one of the important branches of management competency research. HR professionals' competency is an important factor that helps to achieve good performance and sustainable competitiveness for enterprise. Wilhelm (1995) proposed an HR professionals' competency model which composed by three dimensions including business competency, HRM skills competency and change management competency.[7] Ulrich conducted(1995) a survey of 12698 HR professionals and showed that the HR professionals' competency included business knowledge, HR delivery, change management and they need more related knowledge on financial management, internal/external competition and consumer demand [8]. Gu Qinxuan, Zhu $\mathrm{Mu}(2001)$,made a questionnaire survey of HR professionals from enterprises in Shanghai and students majoring in human resource management from Shanghai Jiao Tong University. And the result showed that trustworthiness, competency in solving problems, communication ability, HR professional knowledge, learning ability and other variables have great influence on HR competency. Chen Wansi, Ren Wei, Yao Shengjuan et al. (2006) developed a measuring scale of HR professionals' competency in enterprises of China with high reliability and validity. They established the HR professionals' competency model which divided the competency into two dimensions including functional competency and personal competency. And they made an empirical analysis to prove the fact that the high performance group had significant differences on 13 competency items with general ones.[9] Chen Wansi, Zhao Shuming (2010) took the human resources directors(HRD) from China best employers as an example. They constructed a competency model of HRD including four components as follows: strategic management competency, change management competence, functional management competence and employee relationship management competency. [10]

The study of HR professionals' competency has a history of more than 20 years abroad. They have accumulated rich achievements and experience, especially in the model building and the projects management. In China, the research on HRM competency is still in the stage of exploration and it needs more intensive study in the field, in particular to apply the competency theory to practice and focused on different industries, different enterprises and different objects.

\section{Selection of HR professionals' competency model}

In order to improve the efficiency and effectiveness of the study, we adopted the Chinese enterprise HR professionals' competency model developed by Chen Wansi et al. This model divided the competency into two dimensions including functional competency and personal competency. The measuring scale of HR professionals' competency in enterprises of China passed the internal consistency test and the Cronbach coefficients of the factors were above 0.9 which implied that the scale had a high degree of internal consistency.

In the empirical analysis of Chinese enterprise HR professionals' competency model, Chen Wansi et al. made a hypothesis test and Mann Whitney U Test and then found that the high performance group of HR professionals had significant difference $(\mathrm{p}<0.05)$ with and general ones in 13 
competency factors which could be summarized as functional competency and personal competency.(Table 1) Therefore, this study will be based on this functional-personal competency model, and made a questionnaire survey and empirical analysis to verify the relationship between the 13 competency factors and enterprise performance.

There are many types of indicators to measure an enterprise performance, such as return on equity (ROE), operating profit margin and the index system of the balanced score card (BSC) etc. According to the characteristic of the trade industry, we selected the indicator ROE as the measure of enterprise performance. Because ROE considered both the operating income and the assets of the enterprise scale, thus enterprises with different scale can make a transverse comparison on their performance through the ratio index. It improves the comparability of the indicators.

Table 1 Behavior description of functional-personal competency model

\begin{tabular}{|c|c|}
\hline \multicolumn{2}{|c|}{ Functional competency } \\
\hline Winning support & $\begin{array}{l}\text { Keep good relationship with internal and external departments, in order to } \\
\text { win support on the work }\end{array}$ \\
\hline Set examples & Set a good example for others \\
\hline Effective allocation & Good at the task decomposition, and rank the tasks with some principles \\
\hline Self-confidence & Have confidence in professional judgment and ability \\
\hline Inspiration & Praise or compliment others' achievements in public and inspire them \\
\hline Charisma & Be able to inspire enthusiasm of the team \\
\hline Increasing Morale & $\begin{array}{l}\text { Can promote the friendly atmosphere and make people to achieve the } \\
\text { goal }\end{array}$ \\
\hline \multicolumn{2}{|l|}{ Personal competency } \\
\hline Confidentiality & $\begin{array}{l}\text { Respect the confidentiality of personal information and keep the secret of } \\
\text { business and employees' privacy }\end{array}$ \\
\hline HRM knowledge & Master HRM professional knowledge and practical skills \\
\hline Persistence & $\begin{array}{l}\text { In the face of difficulties and pressures at work, can adjust their attitudes } \\
\text { and stick to the goal }\end{array}$ \\
\hline Renew Knowledge & Active learning new skills and new knowledge \\
\hline HRMIS application & Skilled in use of HRMIS to carry out the work \\
\hline $\begin{array}{l}\text { Business } \\
\text { knowledge }\end{array}$ & Understand all most of knowledge in the fields of enterprise management \\
\hline
\end{tabular}

\section{Research method}

\section{Research design}

In order to understand the role of the HR professionals' competency in enterprise's development, this study adopted the Chinese enterprise HR professionals' competency model developed by Chen Wansi et al. and made a questionnaire survey of HR professionals from the enterprises in petrochemical trade industry. After the statistics and analysis, we found that some HR professionals' competency factors were significantly related to the enterprise performance. And we compared the competency factors which was associated with the performance significantly with current situation of HR professionals' competency, and then found out the weakness of competency. We hope to provide certain decision references for the enterprises to improve their performance.

\section{Instrument}

This study adopted the questionnaire survey based on the measuring scale of HR professionals' competency in enterprises of China and made some supplement and modifications according to the characteristics of the petrochemical trade industry. A Likert scale was used on the questionnaire 
with the following ratings: 5 means the behavior description is very important to HRM; 4, important; 3, general; 2, not important; 1, extremely unimportant. Finally we would use SPSS 20.0 to make correlation analysis, regression analysis and variance analysis based on the data.

\section{Sample}

In this study, we choose HR professionals from the petrochemical trade enterprises in Guangzhou and Foshan region as the sample. Questionnaires were sent by E-mails to the relevant HR managers and entrusted them to collect the data and send back to us. At last, we received a total of 181 questionnaires, but 43 questionnaires were invalid due to the incomplete data. Therefore, we analyzed the rest of 138 valid questionnaires. Among the samples, men accounted for 57.62\%, women accounted for $42.38 \%$. The respondents with master degree or above accounted for $6.83 \%$, with bachelor's degree accounted for $53.68 \%$, with junior-college degree accounted for $36.06 \%$, and the rest $3.43 \%$ was the senior high school degree or below. It was showed that HR professionals' education background of petrochemical trade in the enterprises in this region was mainly bachelor and junior college degree, and the number of men was more than women.

\section{Analysis}

\section{Descriptive statistics}

From the survey data, the top 50\% competency factors of the functional-personal competency model according to its importance were as follows: increase morale, winning support, sense of confidentiality, HRM professional knowledge, charisma, application of HRMIS and inspire others. It was showed that HR professionals generally believed that the competency factors above were the most important ones in the petrochemical trade industry. In addition, there were 4 factors from the professional competency and 3 factors from the personal competency. (Table 2)

Table 2 Descriptive statistics

\begin{tabular}{llcccc}
\hline Competency & Factors & Mean & Std. deviation & N & Rank \\
\hline Functional & Winning support & 4.51 & .69 & 138 & 2 \\
competency & Setting examples & 3.74 & .80 & 138 & 12 \\
& Effective allocation & 4.00 & .92 & 138 & 10 \\
& Self-confidence & 4.13 & .71 & 138 & 8 \\
& Inspiration & 4.18 & .91 & 138 & 7 \\
& Charisma & 4.29 & .74 & 138 & 5 \\
Personal & Increasing morale & 4.54 & .57 & 138 & 1 \\
competency & Confidentiality & 4.45 & .58 & 138 & 3 \\
& HRM knowledge & 4.40 & .67 & 138 & 4 \\
& Persistence & 3.54 & .80 & 138 & 13 \\
& Renew Knowledge & 4.02 & .72 & 138 & 9 \\
& HRMIS application & 4.30 & .85 & 138 & 6 \\
& Business knowledge & 3.93 & .74 & 138 & 11 \\
\hline
\end{tabular}

\section{Correlation analysis}

We used the software of SPSS 20.0 to make a correlation analysis on the sample data, and generated a correlation coefficient of report as table 2. According to the data, it was reflected that these 13 competency factors of functional-personal competency model were not all significantly related to the enterprise performance in the industry of petrochemical trade. Among these factors, winning support, effective allocation, inspiration, HRM professional knowledge, application of HRMIS and business knowledge had significant correlation with the enterprise performance. As 
table 3 the correlation coefficient (Spearmen's $\rho$ value) were 0.568 (Sig.< 0.05), 0.463 (Sig.< 0.05), 0.05 (Sig.< 0.05), 0.742 (Sig.< 0.05), 0.442 (Sig.< 0.05), 0.05 (Sig.< 0.05). And other competency factors such as setting an example, self-confidence, charisma, increasing morale, sense of confidentiality, persistence, renew knowledge couldn't pass the significance test with the enterprise performance (Sig.> 0.05).

Table 3 The correlation coefficient

\begin{tabular}{|c|c|c|c|}
\hline & Spearmen's $\rho$ analysis & ROE & Spearmen's $\rho$ analysisROE \\
\hline \multirow[t]{3}{*}{ Winning support } & correlation coefficient & $.568 *$ Confidentiality & correlation coefficient .054 \\
\hline & Sig.(two-tailed) & .000 & Sig.(two-tailed) \\
\hline & $\mathrm{N}$ & 138 & 138 \\
\hline \multirow[t]{3}{*}{ Setting examples } & correlation coefficient & .085 HRM knowledge & correlation coefficient $.742 *$ \\
\hline & Sig.(two-tailed) & .384 & Sig.(two-tailed) \\
\hline & $\mathrm{N}$ & 138 & 138 \\
\hline \multirow[t]{3}{*}{ Effective allocation } & correlation coefficient & $.463 *$ Persistence & correlation coefficient .062 \\
\hline & Sig.(two-tailed) & .000 & Sig.(two-tailed) \\
\hline & $\mathrm{N}$ & 138 & $\mathrm{~N}$ \\
\hline \multirow[t]{3}{*}{ Self-confidence } & correlation coefficient & .076 Renew Knowledge & correlation coefficient .094 \\
\hline & Sig.(two-tailed) & .824 & Sig.(two-tailed) \\
\hline & $\mathrm{N}$ & 138 & 138 \\
\hline \multirow[t]{3}{*}{ Inspiration } & correlation coefficient & $.433^{*}$ HRMIS application & correlation coefficient $.442 *$ \\
\hline & Sig.(two-tailed) & .000 & Sig.(two-tailed) \\
\hline & $\mathrm{N}$ & 138 & 138 \\
\hline \multirow[t]{3}{*}{ Charisma } & correlation coefficient & \multicolumn{2}{|c|}{ Business knowledge correl } \\
\hline & Sig.(two-tailed) & .912 & Sig.(two-tailed) \\
\hline & $\mathrm{N}$ & 138 & $\mathrm{~N}$ \\
\hline \multirow[t]{3}{*}{ Increase Morale } & correlation coefficient & .068 & \\
\hline & Sig.(two-tailed) & .629 & \\
\hline & $\mathrm{N}$ & 138 & \\
\hline
\end{tabular}

*. Correlation is significant at the 0.05 level (two-tailed).

Table 4 Regression analysis

\begin{tabular}{llcc}
\hline model & $\mathrm{R}$ & $\mathrm{R}^{2}$ & $\operatorname{adj} \mathrm{R}^{2}$ \\
\hline 1 & $.615^{\mathrm{b}}$ & .378 & .349
\end{tabular}

${ }^{a}$ Dependent variable: enterprise performance

${ }^{\mathrm{b}}$ Predictors:(constant), winning support, effective allocation, inspiration, HRM knowledge, HRMIS application, business knowledge.

Table $5 \beta$ coefficient

\begin{tabular}{ll}
\hline & $\beta$ \\
\hline Winning support & .279 \\
Effective allocation & .064 \\
Inspiration & .218 \\
HRM knowledge & .046 \\
HRMIS application & .176 \\
Business knowledge & .122 \\
\hline
\end{tabular}


Table 6 Anova $^{\mathrm{a}}$

\begin{tabular}{llllll}
\hline & Sum of squares & df & Mean square & F & Sig. \\
\hline Regression & 19.573 & 6 & 2.262 & 8.319 & $.000^{\mathrm{b}}$ \\
Residual & 32.155 & 82 & .392 & & \\
Total & 51.728 & 88 & & & \\
\hline
\end{tabular}

${ }^{\mathrm{a}}$ Dependent variable: enterprise performance

${ }^{b}$ Predictors:(constant), winning support, effective allocation, inspiration, HRM knowledge, HRMIS application, business knowledge.

\section{Regression analysis and variance analysis}

We made a regression analysis based on the competency factors which had significantly correlation with enterprise performance, and got coefficient $\mathrm{R}=0.615, \mathrm{R}^{2}=0.378$ and adjusted $\mathrm{R}^{2}=0.349$. These indexes showed that about $34.97 \%$ of the variation of enterprise performance could be explained by the multivariate regression model. The $\beta$ coefficient represented the contribution degree of these 6 competency factors to enterprise performance. And we found that the competency factors such as winning support, inspiration, HRMIS application, business knowledge had higher contribution degree than other factors on enterprise performance. Table 6 was the variance analysis (ANOVA) and the F-value was 8.319 which was less than the critical value of $\mathrm{F}(4.85)$ with degrees of freedom 6 and 131(Sig.<0.05). It means that there is no linear relationship between enterprise performance and these competency factors at the significance level of 0.05 .

\section{Suggestions}

\section{The role of HR should transform to business partner}

With the increasingly fierce market competition, enterprises in China have to face the market environment which is of uncertainty and complexity, and the role of human resource management (HRM) is transforming to the role of human resource business partner (HRBP). As the role of HRBP, it needs to adjust the HRM strategy according to the change of environment and strategy in a macro view. And they should focus on specific human resource management and strengthen the cooperation with other departments from a micro view to win necessary support. Besides, it needs to analysis the demands of talents who are vital to the development of enterprise, so as to improve their motivation efficient. To HR individuals, they should change their conception of traditional personnel administration and have a better understanding the role of HRM. HR professionals should think of the management in the view of strategy and promote the progress by the concept of HRBP. Enterprises should pay more attention to the trend of this transformation from personnel administration to HRBP, and get HR into operation management and strategic decision.

\section{HR should strengthen the training of professional and business knowledge}

According to the survey data and interviews, most HRM are still in the junior stage currently, and weak in business knowledge especially in business process, market environment and operation management. With the transformation of HRM, especially the particularity of HRBP, HR professionals need to manage the existing human capital, but also predict and manage the business think-tank effectively in the future to obtain a lasting development.

Therefore, HR should master professional knowledge and tools, but also need to understand the operation of enterprise, including the value chain, business process, the main source of profit and the competition environment, etc. so as to provide a better support to business. HR professionals should be initiative to renew their professional knowledge and expand the scope of business knowledge. Enterprises should pay more attention to the training on professional and business knowledge and provide a platform and opportunity to their employees to become more professional.

\section{Enterprise and HR department should allocate the resource effectively and promote the HR competency comprehensively}

It is a long-term and arduous task to improve the competency of HR professionals 
comprehensively. In this study we found that the HR professionals' competency of effective allocation has an important contribution to the enterprise performance. Therefore, great efforts should be made to improve HR professionals' competency of effective allocation and enterprise should also empower the HR departments of scheduling resources. The comprehensive promotion of HR professionals' competency needs a mutual process both in capacity and empowerment.

Enterprise and the human resource department should allocate financial resource and human resource effectively. They should ensure that there is enough resource for continuous enhancement, and take the cost-effectiveness into consideration. In terms of the allocation of financial resource, they should ensure enough funds to enhance the competency and focus on improving the current weakness such as marketing, financial management, operation management, supply chain management and other business knowledge. In terms of the allocation of human resource, they should establish a competency system and select talents with high competency for enterprise. It is necessary to design series of corresponding training programs and performance \& compensation system to promote the virtuous circle of the competency.

\section{Enterprise should increase investment in the construction of HRMIS}

With the advent of big data era, the informationization of HRM has become an important part to enterprise to build their core competitiveness. As a column published in the New York Times in February 2012 wrote, "big data" era is coming, the decision in the commercial, economic and other fields will be increasingly made based on data and analysis but not based on experience and intuition. Human resources management involves a lot of quantitative data and quantitative information. It is junior information technology applications to use office software to deal with daily operation, but it becomes increasingly difficult to deal with the complex competition situation. Enterprise should strengthen the construction of human resource management information system (HRMIS), including the investment in hardware and software. Based on the analysis of large amounts of data, enterprise can realize the target of scientific and precise management and estimate the supply and demand of human resource scientifically. In addition, HRMIS can help to measure the competency level of staff and evaluate their performance. According to the reference data, enterprise can offer more individuality motivation to different staff and supervise the change of labor cost. All of these can optimize the efficiency of human resource management.

\section{Conclusion}

This study applied the functional-personal competency model to the specific region and industry. We verified the relationship between enterprise performance and HR professionals' competency in petrochemical trade industry of Guangzhou and Foshan region in China through the quantitative statistical analysis method. Even there is no linear relationship between enterprise performance and these competency factors, we can't predict the enterprise performance through the competency accurately, the results of this study, to a certain extent, reflected the fact that these competency factors had different contribution to the enterprise performance. So the enterprises in this industry should make an effort to improve the HR competency which has significant correlation with enterprise performance such as winning support, effective allocation, inspiration, HRM professional knowledge, application of HRMIS, business knowledge etc. to improve the enterprise performance.

\section{Acknowledgement}

This research was financially supported from the key programs of the Postgraduate Innovation by Southwest University for Nationalities. (No. CX2014SZ02)

\section{References}

[1] David C. McClelland. Testing for Competency Rather Than Intelligence, American Psychologist, 1973(28):1-14. 
[2] Lyle M. Spencer, Sige M. Spencer. (translated by Wei Meijin), Shantou university press, 2003.

Reference to a book: Talent evaluation method: establish an excellent performance mode.

[3]Ulrich D., Brockbank W., Yeung A.,\&Lake D. .Human resource competencies and empirical assessment. Human Resource Management,1995,34(4):473-496.

[4]Wang Chongming. KSAOs. Knowledge, Skill, Attitude and Others. Management psychology. People's Education Press, 2000.

[5]Peng Jianfeng, Jing Xiaojuan. Staff quality model design [M]. People's Education Press,2003.

[6] Information on http://www.china-rand.com/temp/renli/.

[7]Wilhelm W. R.. Response to Reexamining professional certification in Human Resource Management by Carolyn Wiley. Human Resource Management, 1995, 34(2):295-297.

[8]Ulrich D.,Brockbank W.,Yeung A., \&Lake D.. Human resource competencies and empirical assessment. Human Resource Management, 1995, 34(4): 473-496.

[9]Chen Wansi, Ren Wei, Yao Shengjuan. Empirical study based on Chinese enterprise human resource management competency model. East China economic management, 2006(12): 96-100.

[10]Chen Wansi, Zhao Shuming. Competency model research of human resources director from China best employers. Journal of management, 2010(9): 1308-1315. 